\title{
FIL2, an extracellular Leucine-Rich Repeat protein, is specifically expressed in Antirrhinum flowers
}

\author{
Markus Steinmayr, Patrick Motte, Hans Sommer, \\ Heinz Saedler and Zsuzsanna Schwarz-Sommer* \\ Max-Planck-Institut für Züchtungsforschung, 50829 Köln, \\ Germany
}

\section{Summary}

The expression of the Antirrhinum gene FIL2 is affected in mutants of the homeotic transcription factor DEFICIENS. Northern and Western blot analyses showed that FIL2 in wild-type Antirrhinum flowers is expressed weakly in the petals and more abundantly in the reproductive organs; the gene is active in the filaments and anthers of stamens, and in the stigma and transmitting tissue of the carpels. The FIL2 protein is glycosylated with high mannose type glycan chains and is located in the middle lamella of the extracellular matrix. The amino acid sequence contains 10 tandem repeats, the composition of which is similar to the Leucine-Rich Repeat (LRR) motif found in mammals, Drosophila and yeast. The possiblity that FIL2 might be a component of a cellular signalling mechanism, involving LRR-mediated protein-protein interactions is discussed.

\section{Introduction}

Floral organs consist of highly specialized tissues and differ structurally and functionally from each other and from all other organs of the plant. Floral organogenesis, therefore, must be controlled by differential activation of tissue- and organ-specific genes. Indeed, several homeotic genes controlling the formation of floral organs in Antirrhinum and Arabidopsis have recently been cloned (Coen and Meyerowitz, 1991; Schwarz-Sommer et al., 1990) and they all show homology to known transcription factors. These homeotic genes presumably control the expression of a range of target genes. Organ-specific target genes may be involved in organ formation either by extending the regulatory cascade of control events, or by performing structural or biochemical functions which are crucial for the structure and physiology of the organ.

One particular function of organ-specific genes may be their involvement in signal transduction, enabling cells to communicate with each other. In plants, information about

Received 21 July 1993; revised 2 November 1993; accepted 15 December 1993.

* For correspondence (fax + 492215062113 ). the molecular mechanisms which underlie cell communication is scant. Processes related to fertilization, such as the compatibility reaction between the pollen and the stigma (Nasrallah et al., 1988) and the subsequent growth of the pollen tube through the transmitting tissue of the style (Lord and Sanders, 1992), are model systems in studying cell communication. In these cases, cell-to-cell communication appears to be mediated by interactions between extracellular matrix (ECM)-located glycoproteins (SLG), which display homology to the extracellular domain of a receptor kinase (SRK; Stein et al., 1991). Both proteins probably interact by binding to the same, as yet unidentified, ligand. In animal systems the role of the ECM in cell interactions is well documented (Bronner-Fraser (ed.), 1990; Ruoslahti, 1989), and in some of these processes Leucine-Bich Bepeats (LRR) containing proteins were shown to be involved due to their ability to bind specifically to other proteins (Braun et al., 1991; Yamaguchi and Ruoslahti, 1991). Almost every LRRcontaining protein is either located entirely within the ECM or at least the LRR domain is exposed to the extracellular space.

In this paper we report the isolation, structure and expression pattern of the FIL2 gene, which encodes an LRR protein, and is putatively involved in the cell communication essential for the proper development and/or function of petals, stamens and carpels in Antirrhinum majus.

\section{Results}

\section{Isolation of FIL2}

Mutants of the homeotic DEFICIENS gene (DEFA) in Antirrhinum majus display sepal-like structures instead of petals and carpel-like structures instead of stamens (Schwarz-Sommer et al., 1990). DEF A, a MADS-box protein encoded by the DEFICIENS gene, reveals homology to transcription factors and most likely is involved, directly and indirectly, in activating petal- and stamen-specific genes. In order to isolate organ-specific genes, the expression of which are affected by a mutation in the DEFICIENS gene, several clones, including FIL2, were isolated by differential screening of a wild-type flowerspecific CDNA library as previously described (Sommer et al., 1990). FIL2 was named by virtue of its early expression in the filaments of young flower buds at the developmental stage used for the differential screening procedure (not shown). Subsequent analyses, however, 
have shown that FIL2 expression during later stages is not restricted to the filament.

\section{Sequence analysis of FIL2}

The 1170 bp full-length FIL2 cDNA contains an open reading frame encoding a 330 amino acid protein (Figure 1). The hydrophobic $\mathrm{N}$-terminus of the deduced FIL2 protein reveals features of a signal peptide for extracellular localization of the protein (von Heijne, 1986). The amino acid sequence displays two possible phosphorylation sites and eight putative glycosylation sites for $\mathrm{N}$-linked glycosyl chains.

The region spanning from amino acid 85 to 323 contains 10 tandem repeats with an average size of 24 amino acids: 13 of the 24 residues are conserved (Figure 2a).

(a)

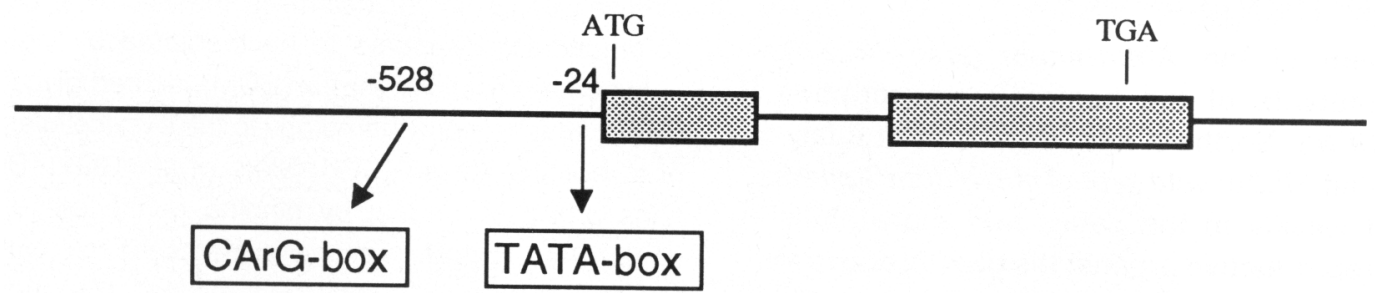

$1 \mathrm{~kb}$

CC TIITTG GG TATATATATA

(b)

\begin{abstract}
CAAATCTCCACACATTAGCCACCATGAAGATAACTTTCCTTTTGGTACTTTCTCTGCTTGCTCTTTTPTCTCAGCCTTTTCTCTCTCAAGCAGAAAGATG 100 $\begin{array}{lllllllllllllllllllllllllll}M & K & I & T & F & L & L & V & L & S & L & L & A & L & F & S & Q & \text { P } & F & L & S & Q & A & E & R & C\end{array}$ CCACCCTCAAGACAAAAGAGTACTCTTGAAAATCAAAAAAGCCTTCAACAATCCCTACCACTTGGCCTCATGGATCCCGGACACCGACTGCTGCTCCIGG 200

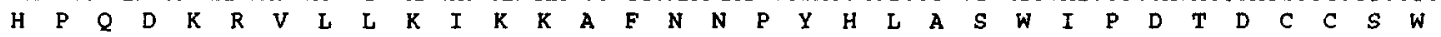
TACGTGGTCGAGTGCGATCGCACGACCAACCGCATCAACGACTTCCACCTCTTCTCCGCCAGTGTCTCTEGCCAGATCCCCGAAACCATTGCCGAGCTCC 300

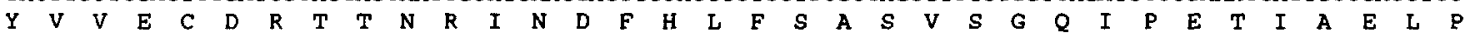
CGTTCCTCGAGTCCCTAATGTTCCGCAAAATTACCAATCTTACTGGGACAATCCCGCATGCCATTACCAGGCTTACTCGTCTGAGGTCACTCACTATCAG 400 $\begin{array}{lllllllllllllllllllllllllllllllllll}F & L & E & S & L & M & F & R & K & I & T^{+} & N^{\star} & L & T & G & T & I & P & H & A & I & T & R & L & T & R & L & R & S & L & T & I & S\end{array}$ CTGGACCAACATTTCCGGCCCCGTTCCCGCATTCCTCAGCGAGCTCAAAAAACCTTACAAGCCTCGACCTATCATTCAACAACCTCAGTGGCTCGATCCCT 500

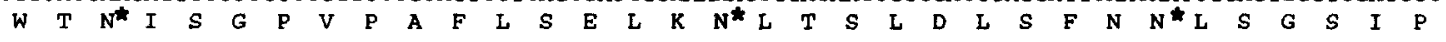
CCATCGCTTATCCAGCTCAGAAACCTTAACGATATGCGTTTAGACCGgAACAAACTCACGgGAaCATCCCCGAATCATTTGGAaATTTGACCCCGAGTC

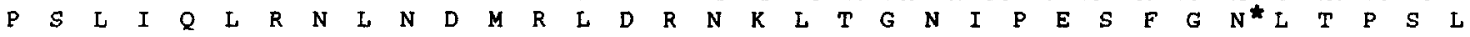
TTCAGTACCTTTACCTATCTCACAATCAGCTTTCGgGCATTCCACGAGCTTTAGGGGACCTAAACTTAACTTCGATCGAGCTGCAACGCAACAGGCTTGA $\begin{array}{llllllllllllllllllllllllllllllllllll}Q & Y & L & Y & L & S & H & N & Q & L & S & G & I & P & R & A & L & G & D & L & N^{*} & L & T & S & I & E & L & Q & R & N & R & L & E\end{array}$ AGGCGACGTATCGTTCATGTTTGGAAGAAACAAGACTATACAATATGCTGATTTTTCGAGGAACATGTTGCAGTTTGATTTGTCACACGTGGAATTCCCG 800 $\begin{array}{llllllllllllllllllllllllllllllllllll}G & D & V & S & F & M & F & G & R & N^{*} & K & T & I & Q & Y & A & D & F & S & R & N & M & L & Q & F & D & L & S & H & V & E & F & P\end{array}$ GACAGTTTATCGTCGTTGGACTTGAATCATAACAGGATTACTGGGAGCTITGCAGAGGGTTTGACTAAACTGGAGTCGCTTTATAATCTGAACGTGAGTT $\begin{array}{lllllllllllllllllllllllllllllllllll}D & S & L & S & S & L & D & \text { L } & N & \text { H } & \text { N } & R & \text { I } & \text { T } & \text { G } & S & \text { L } & \text { P } & \text { E } & G & \text { L } & \text { T } & \text { K } & \text { L } & \text { E } & S & \text { L } & \text { Y } & \text { N } & \text { L } & \text { N } & \text { V } & S & \text { S }\end{array}$ ATAACAGGCTGTGCGGTAAGATTCCGGTTGGCGGAAGCTGCAAGAATTGGACTACACCGCGTATTTTCATAACAGATGCTTGTGTGGTGCGCCATTGCC 1000 $\begin{array}{llllllllllllllllllllllllllllllllllll}N & R & L & C & G & K & I & P & V & G & G & K & L & Q & E & L & D & Y & T & A & Y & F & H & N & R & C & L & C & G & A & P & L & P\end{array}$

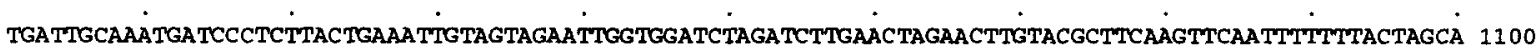
D C K

ATAAAGTTTGTAACTTTCTTCACTTGTAGTATGGGATTTAAAGCTCTAACCATTGAGCATTTGACTGGTTAAAAAAA
\end{abstract}

Figure t. Structure of the FIL2 gene (a) and nucleotide and deduced amino acid sequence of the FIL2 cDNA (b).

The scheme at the top shows the structure of the F/L2 transcription unit. Shaded boxes represent exons where the sites for initiation and termination of translation are indicated. The positions of a putative TATA-box and a CArG-box are shown together with the corresponding sequences found in the upstream region of the FIL2 gene.

In (b) the signal peptide as defined by von Heijne (1986) is underlined, and the possible phosphorylation and glycosylation sites are indicated with a cross or an asterisk, respectively. The position of the intron is shown by a triangle. 
(a)

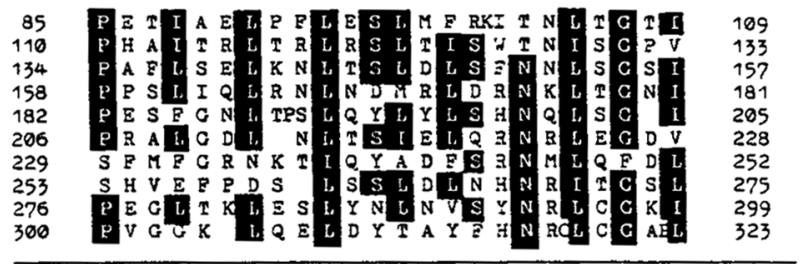

cons. P.: I= I - I I S I = I S $=\mathrm{N}=\mathrm{I}=\mathrm{C}=\mathrm{I} / \mathrm{I} 24$ as

(b)

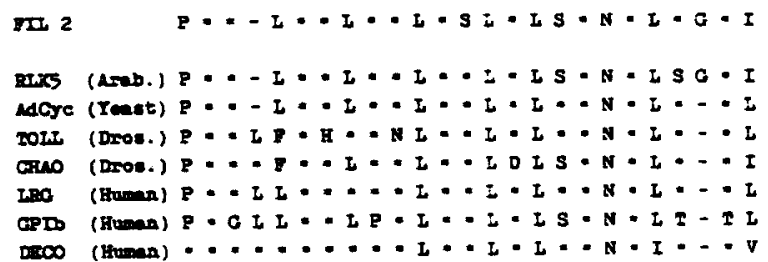

Flgure 2. FIL2 is an LRR-containing protein.

(a) Internal repeat structure of the FIL2 protein. The alignment shows only those residues which are identical in at least five out of the 10 repeats. The position of the first and the last residue of each repeat within the FIL2 protein is indicated at the left and at the right, respectively. The LRR consensus sequence of FIL 2 is shown at the bottom.

(b) Comparison of the LRR consensus sequence of FIL2 and examples of LRR-containing proteins found in other organisms. RLK5, receptor-like protein kinase (Walker, 1993); AdCyc, yeast adenylate cyclase (Kataoka et al., 1985); LRG, leucine-rich $\alpha_{2}$ glycoprotein (Takahashi et al., 1985); TOLL, toll protein (Hashimoto et al., 1988); CHAO, chaoptin protein (Reinke et al., 1988); GPIb: human platelet membrane glycoprotein 1b (Lopez et al., 1987); DECO, decorin protein (Krusius and Ruoslathi, 1986). The residues introduced to obtain an optimal alignment are indicated by dashes.

The composition of the repeats is very similar to the LRR motif found in several other proteins (Figure 2b).

\section{The FIL2 transcription unit}

The genomic FIL2 locus was cloned using a library of recombinant EMBL4 phages as described in Huijser et al. (1992). About $3 \mathrm{~kb}$ of the genomic locus was sequenced, including a $1.5 \mathrm{~kb}$ region upstream of the putative transcription initiation site and $0.5 \mathrm{~kb}$ downstream of the polyadenylation site (Figure 1a). The FIL2 gene reveals two exons ( $371 \mathrm{bp}$ and $799 \mathrm{bp}$ ) which are separated by a $264 \mathrm{bp}$ intron. The promoter region displays a $10 \mathrm{bp}$ TATA-box at position -24 upstream of the putative transcription start and an element at position -528 , which resembles the consensus sequence of the binding site for MADS-box transcription factors (CArG-box; Hayes et al., 1988; Pollock and Treisman, 1991).

\section{Organ specificity of FIL2 expression}

The expression of the FIL2 gene in different organs was determined by Northern and Western blot analyses. In Northern blot experiments with mRNA isolated from different floral organs, the FIL2-specific probe hybridized to a $1.1 \mathrm{~kb}$ RNA in stamens and weakly in petals and carpels (Figure 3a). Plants carrying different mutant alleles of the homeotic DEFICIENS gene contain, as expected from the differential screening procedure, different abundances of FIL2 mRNA (Figure 3b). In the case of the defA-nic and defA-gli alleles, FIL2 transcription is decreased compared with the wild-type. Expression of the FIL2 protein is flowerspecific: the expression is weak in petals, highest in stamens and is also present in carpels (Figure 4a). During flower development the earliest stage at which FIL2 protein expression was detected was in buds of 2-3 mm length (not shown). Interestingly, comparison of FIL2 expression in stamens and pistils reveals increasing amounts of FIL2 protein in this part of the female organ during maturation, whereas stamens contain an almost constant level of FIL2 during development (Figure 5).

\section{Chemical modification of FIL2}

The expected size of the FIL2 protein is approximately $35 \mathrm{kDa}$, as calculated from the size of the cDNA. However, a molecular weight of $45 \mathrm{kDa}$ was estimated in Western (a)
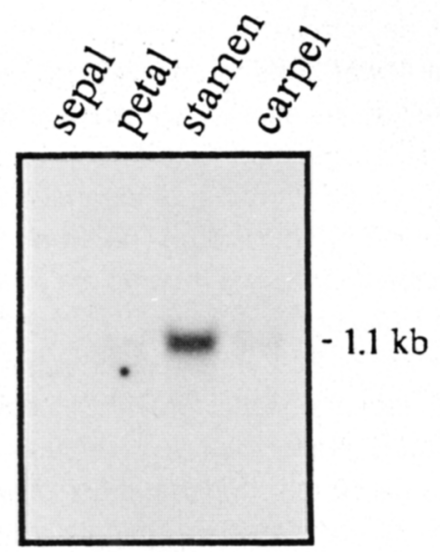

(b)
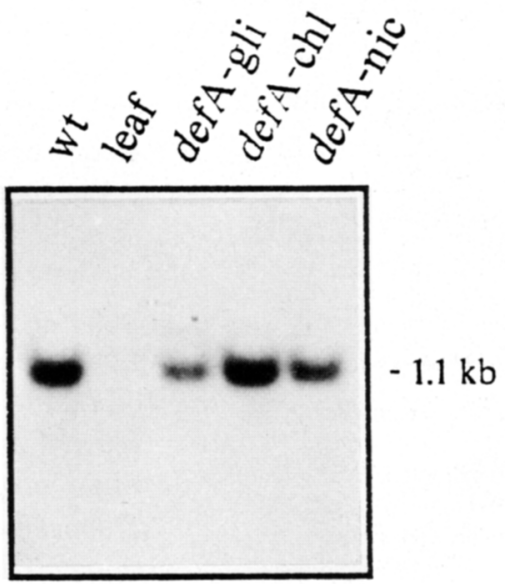

Figure 3. Transcription of the FIL2 gene in dissected organs of WT flowers (a) and in flowers of different mutant alleles of the DEFICIENS gene (b).

For the Northern blot presented in (a) $2 \mu \mathrm{g}$ poly $(A)^{+}$mRNA, isolated from different organs of 10-15 mm buds were probed with radioactively labelled FIL2 cDNA.

In (b), expression of the FIL2 gene in plants carrying different mutant alleles of DEFICIENS was analysed by using $2 \mu \mathrm{g}$ poly $(A)^{+}+\mathrm{mRNA}$ isolated from 10-15 $\mathrm{mm}$ WT and mutant buds. $w t$ wild-type; defA-gli, defA-globifera; defA-chl, defA-chlorantha; defA-nic, defA-nicotianoides. 
(a)

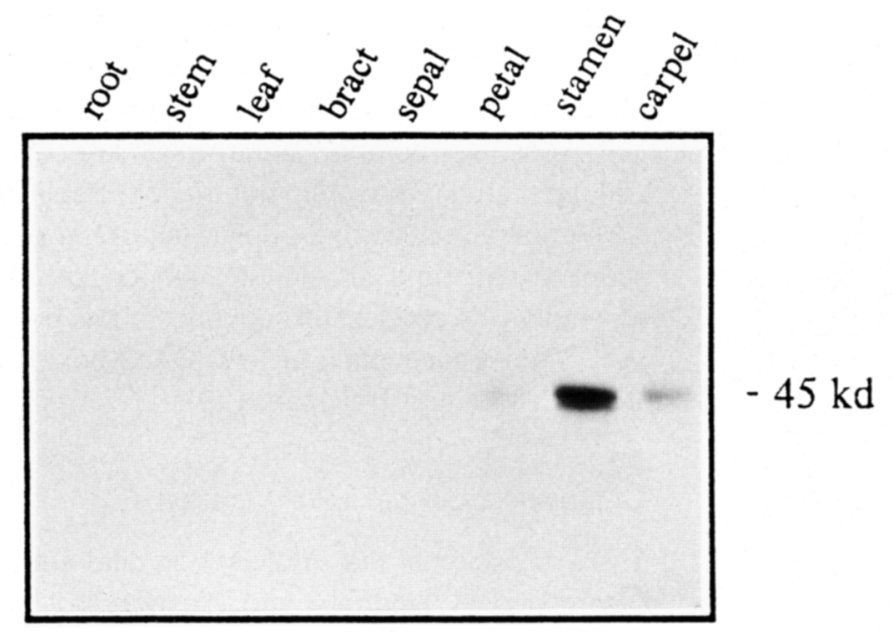

(b)

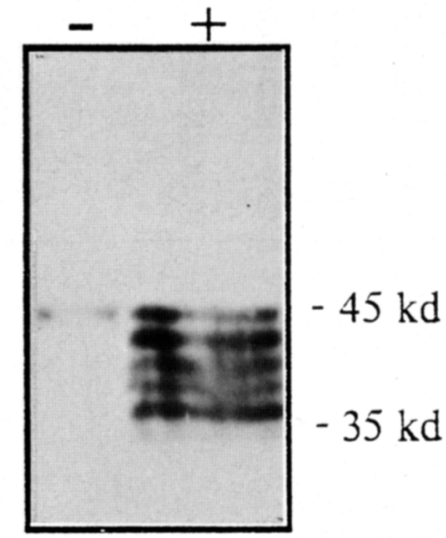

Figure 4. Organ-specific expression (a) and chemical modification (b) of the FIL2 protein.

The Western blot shown in (a) was prepared by using $5 \mu \mathrm{g}$ protein isolated from different vegetative and floral organs of $A$. majus (see Experimental procedures).

In (b), the chemical modification of the FIL2 protein was investigated by partial digestion of $100 \mu \mathrm{g}$ stamen proteins with $2 \mathrm{u}$ of $\mathrm{N}$-glycosidase $\mathrm{F}$ (see Experimental procedures). The reaction was stopped after different incubation times and the samples were mixed (+). As a control, $10 \mu \mathrm{g}$ stamen protein were incubated without $\mathrm{N}$-glycosidase $F(-)$. The affinity-purified FIL2-specific antiserum was used to detect the FIL2 protein.

blot experiments, using stamen protein extracts and a FIL2-specific polyclonal antiserum (Figure 4). To elucidate whether the unexpected size of the protein was due to chemical modification such as $\mathrm{N}$-linked glycosylation, protein preparations from stamen were incubated with $\mathrm{N}$-glycosidase $\mathrm{F}$ and subjected to SDS-PAGE (see Experimental procedures). After such treatment the FIL2 protein migrated with the expected size of $35 \mathrm{kDa}$ in

\section{stamen pistil}

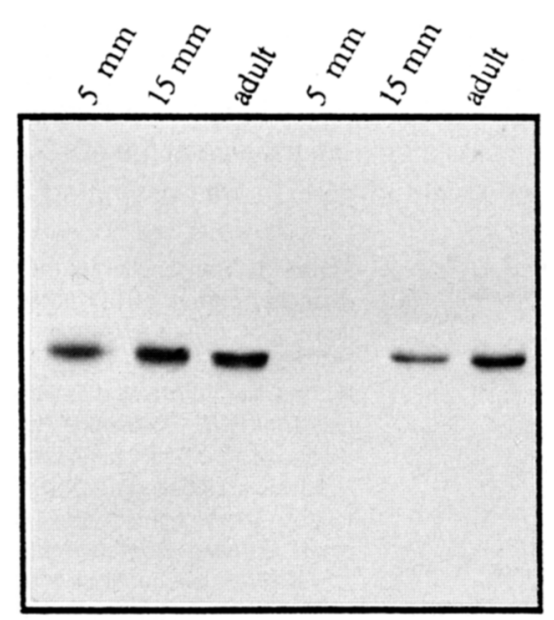

Figure 5. Expression of the FIL2 protein in stamens and pistils during maturation of the flower.

For Western blot analysis the proteins were extracted from organs dissected from $5 \mathrm{~mm}$ buds (lane 1 and 4), from $15 \mathrm{~mm}$ buds (lane 2 and 5 ) and from adult flowers (lane 3 and 6 ). Pistil proteins were prepared after discarding the lower part of the carpels. Each lane contains $5 \mu \mathrm{g}$ protein.
Western blot experiments. Partial cleavage by the same enzyme resulted in six different mobilities of the FIL2 protein (Figure 4b). This suggests that in vivo the protein is modified by five glycosyl chains with an apparent molecular weight of approximately $2 \mathrm{kDa}$ each. The native FIL2 protein was retained by a column loaded with the lectin GNA (Boehringer Mannheim), indicating that at least one of the glycosyl chains has a terminal Man( $\alpha 1-3)$ Man unit, which is typical of high mannose-type glycan chains (Shibuya et al., 1988)

\section{Immunolocalization of the FIL2 protein}

To determine the location of the FIL2 protein in different floral organs, longitudinal and transverse sections of flower buds were incubated with the FIL2-specific antiserum. In stamens of 10-15 $\mathrm{mm}$ flower buds a signal was visible in the filament as well as in the connective, the epidermis and the endothecium of the anthers (Figure 6a and b). FIL2 was not detectable in the vasculature and pollen. The carpels of flower buds at this developmental stage contain the protein in the stigmatic tissue and in the upper part of the transmitting tissue (Figure $6 \mathrm{c}$ ). In adult flowers, expression of the FIL2 protein is extended over the entire transmitting tract (Figure 6d). The weak FIL2 signal obtained in Western blots when complete carpels were used for protein isolation (see Figure 4a) may thus be due to the localization of FIL2 in particular cell types within these organs. In fact, the signal intensity increases when only pistil proteins were analysed (Figure 5a). Transverse sections of 5-10 mm buds revealed a weak signal in petals, which is stronger in the middle of each 

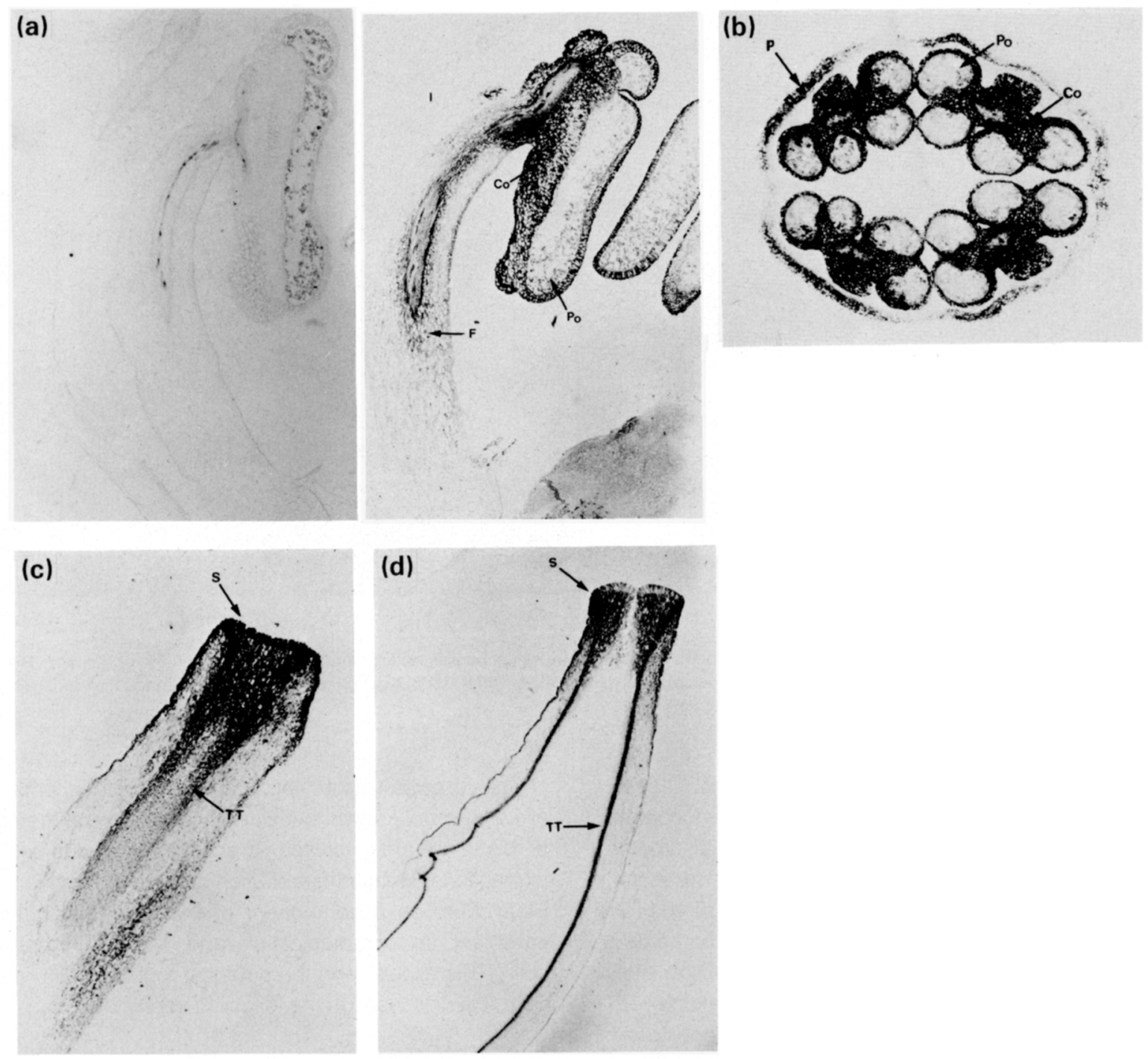

Figure 6. In situ immunolocalization of the FIL2 protein in stamens and pistils of young buds and adult flowers.

Longitudinal (a, $c$ and d) and transversal (b) sections through buds or organs were incubated with the FIL2-specific antiserum and pre-immune serum. The photographs show a longitudinal section of a stamen of a 10-15 mm bud (a) incubated with pre-immune serum (left) and with the FIL2-specific antiserum (right), a pistil of a 10-15 mm bud (c) and a pistil of an adult flower (d), and a transversal section through the lower part a 5-10 mm bud at a position where the petals are fused and form a tube (b). F, filament; Co, connective; Po, pollen; S, stigmatic tissue; TT, transmitting tissue; P, petal.

organ (Figure 6b). Localization of FIL2 mRNA expression by in situ hybridization with a ${ }^{35} \mathrm{~S}$-labelled antisense RNA probe using tissue of $5 \mathrm{~mm}$ buds was similar to the pattern of protein expression (data not shown).

\section{Subcellullar location of the FIL2 protein}

The amino acid sequence of FIL2 reveals a signal peptide for transport of the protein to the extracellular matrix (ECM). In order to show that FIL2 is located in the ECM, ultrathin sections from filaments of stamens of 5-10 mm buds were incubated with the affinity purified antiserum. The signal obtained with a gold-labelled second antibody was visualized by transmission electron microscopy. The middle lamella of the ECM was the only part of the cell showing a strong signal (Figure 7). FIL2 does not seem to be evenly distributed around the cell, but is often concentrated in the fibrous structure surrounding intercellular spaces. In addition to the signal in the ECM a weak labelling of dictyosomes was visible.

\section{Discussion}

The FIL2 CDNA clone, along with other CDNA clones (Nacken et al., 1991), was isolated by differential screening of wild-type and defA-gli floral cDNA libraries. Hence it was considered possible that the FIL2 gene was both involved in the formation and/or function of floral organs, 

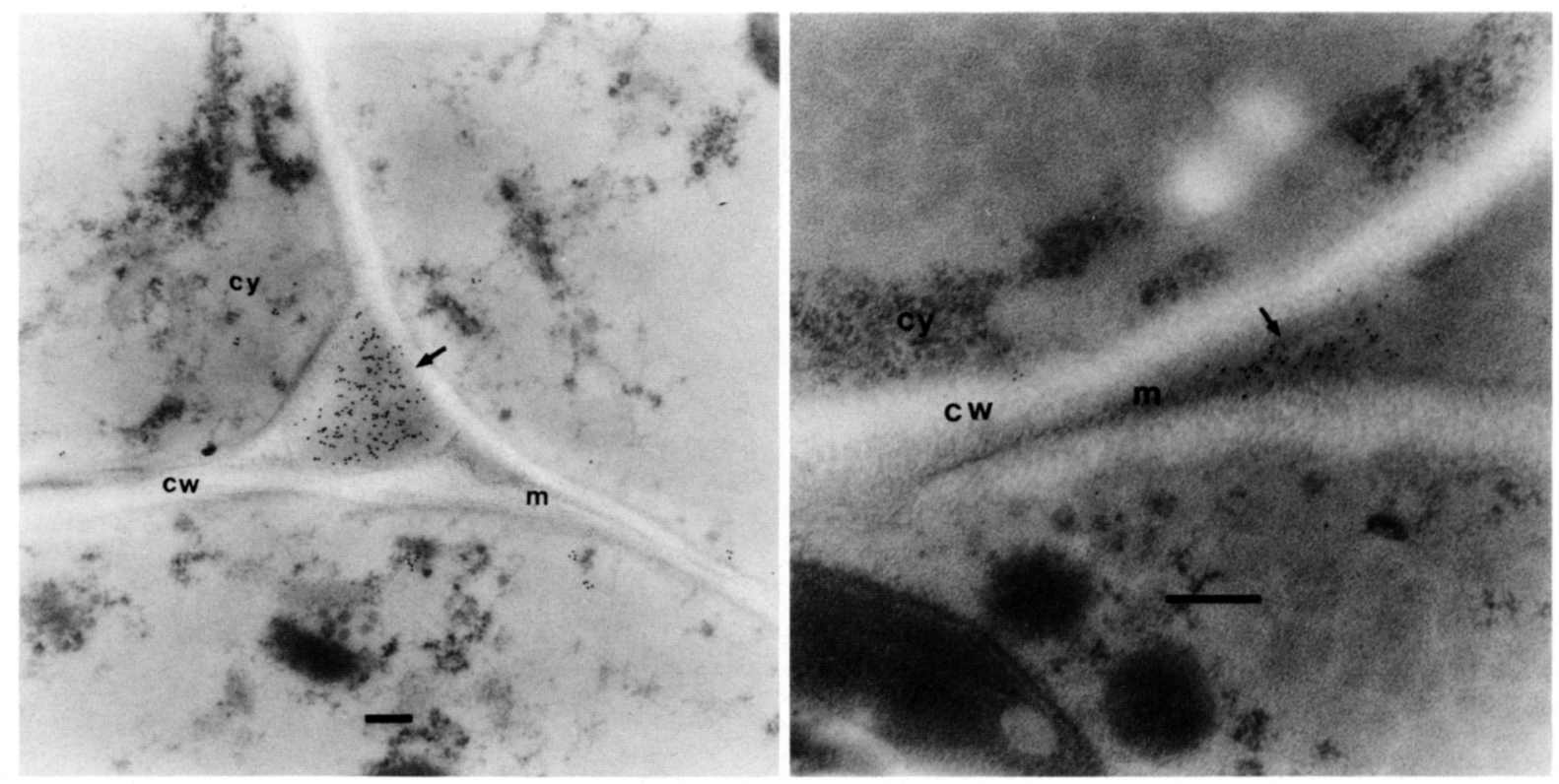

Figure 7. Subcellular localization of the FIL2 protein.

The two independent immunolocalization experiments were performed using ultrathin tangential sections through the filament of a $5-10$ mm bud. The goldlabelled second antibody (see arrowheads) and the cell structures are visualized by transmission electron microscopy. The magnification bars represent $0.25 \mu \mathrm{m}$. cy, cytoplasma; $m$, middle lamella; $c w$, cell wall.

and regulated by the floral homeotic gene DEFICIENS. Sequence analysis revealed that the cDNA encodes a 330 amino acid protein with interesting molecular properties. The FIL2 protein contains a signal peptide for extracellular location at the $\mathrm{N}$-terminus and consists of 10 LRR motifs. Potential post-translational modification of the protein is indicated by the presence of two recognition sites for phosphorylation and eight putative glycosylation sites. Indeed, five glycosylation sites are chemically modified in the FIL2 protein from stamens, and at least one of these sites may be occupied by a high mannose-type glycan chain. By these criteria the FIL2 protein belongs to the family of LRR-containing glycosylated proteins, members of which are also found in several other organisms (Figure 2b). The majority of the LRR proteins from different species are located in the extracellular space and, consistent with this, the FIL2 protein is also located in the middle lamella of the ECM. FIL2 is a flower-specific gene and its expression is temporally and spatially regulated. During early stages of flower development the FIL2 mRNA and the FIL2 protein are expressed weakly in petals and more strongly in the filaments of stamens. In the course of maturation FIL2 expression increases in carpels and becomes strongest in the transmitting tract and in the stigma of the female organ. Whether the spatial and temporal pattern of FIL2 expression reflects a common biological function of FIL2 in different organs, or whether its biological function differs during floral organogenesis remains an open question.
The precise molecular function of LRR-containing proteins is not known, but it seems that several members of this family are involved in processes related to cell-cell interactions during differentiation and growth. By analogy, FIL2 could be a component of the signalling pathway important for communication and interaction between cells. This aspect, and the potential regulation of FIL2 by DEF $A$ is discussed in the following section.

\section{Is FIL2 a target gene of the homeotic transcription factor DEFICIENS?}

The FIL2 gene is expressed in carpels only during late stages of flower development, whereas stamens reveal expression also in younger stages. Consequently, defA-gli flowers, which are void of stamens, do not express the FIL2 gene in the young stages which were used as the source for the construction of the CDNA library. FIL2 was cloned due to its strong expression in wild-type stamens and absence of expression in defA-gii flowers at this early stage of development. The formation of functional and FIL2-expressing female organs in the null mutant defA- gli suggests that carpel development as well as the FIL2 expression in these organs are independent of DEF $A$ function. Nevertheless, altered DEF A gene function does affect FIL2 expression in flowers of plants carrying the mutant defA-nic allele where petals and stamens do develop, although their morphology is aberrant (SchwarzSommer et al., 1992). Furthermore, the FIL2 promoter 
contains a CArG-box which may function as a recognition sequence for MADS-box transcription factors, such as DEF A. Preliminary in vitro binding studies and gel retardation assays indicate that this CArG-box weakly, but . specifically, binds to the DEF AVLO heterodimer obtained by co-translation of the DEF A and GLO cRNAs (Tröbner et al., 1992). Thus, FIL2 expression in stamens could be indirectly or directly regulated by DEF A. Temperature shift experiments with the temperature-sensitive mutant defA-101 which develops normal stamens under permissive conditions (Schwarz-Sommer et al., 1992), might help clarify whether FIL2 expression in stamens is controlled by DEF A.

\section{Possible function of the FIL2 protein in cell-cell communication}

The FIL2 protein is located in the middle lamella of the ECM. In animals the ECM is known to contain components, mainly proteins, that either influence the shape and stability of the cell or are essential for cell-cell interactions during differentiation and growth regulation (see the Introduction). The ECM of plants is suggested to have similar functions (Adair and Mecham, 1990; Roberts, 1990). The idea that FIL2 as a component of the ECM is involved in cell-cell interaction is supported by the structure of the protein. Eighty per cent of the FIL2 protein consists of an LRR domain and in some cases it has been shown that the specific binding of LRR-containing proteins to other polypeptides in the ECM is an essential step in the interaction between cells. For example, DECORIN, an extracellular matrix glycoprotein from mammals, regulates cell proliferation by binding to the growth factor TGF- $\beta 1$ via its LRR domain, thereby inhibiting the interaction between TGF- $\beta 1$ and its receptor (Yamaguchi and Ruoslahti, 1988). A similar interference between a ligand and the corresponding receptor is a possible mechanism for the function of FIL2, as it also is an extracellular glycoprotein with an LRR domain. In this case, FIL2, as a soluble component of a signal transduction system, could either concentrate the ligand nearby the receptor, or, like DECORIN, FIL2 could compete for ligand binding. Both mechanisms implicate the existence of a receptor which binds to the same molecule as FIL2 and shares some characteristics with this protein, such as an LRR domain essential for ligand binding. The existence of a receptor molecule with these characteristics has been demonstrated in plants by the cloning of an Arabidopsis gene with an LRR domain, a transmembrane domain and a protein kinase domain (Walker, 1993). The function of this putative receptor kinase protein is not known. In animals similar LRR-containing receptor proteins, such as the TOLL gene of Drosophila, are involved in the control of morphogenesis (Hashimoto et al., 1988; Schneider et al., 1991).

Systems consisting of a soluble protein and a receptor with similar structural features also exist in plants, like for example the self-incompatibility system with SLG and SRK as components (see the Introduction). The cloning of cDNAs, which are homologous to SRK, but are expressed in vegetative tissues (Tobias et al., 1992; Walker, 1993; Walker and Zhang,1990) suggests that such systems provide a general mechanism for signal transduction in plants (Dzelzkalns et al.,1992). Because FIL2 is perhaps integrated in one of these systems, the demonstration of specific ligand binding capacity of this protein and the elucidation of its function might give some insight into cell communication in plants.

\section{Experimental procedures}

\section{Preparation of mRNA and construction of CDNA and genomic libraries}

Preparation of mRNA, construction of a subtracted cDNA library, differential screening, and Northern blotting techniques were described by Sommer et al. (1990). The construction of the genomic library was performed according to Huijser et al. (1992).

\section{In situ hybridization}

In situ hybridization with ${ }^{35}$ S-labelled antisense RNA was performed according to Huijser et al. (1992).

\section{DNA sequencing}

FIL2-specific cDNA fragments were subcloned into the Bluescript vector (Stratagene). Both DNA strands were sequenced by the chemical degradation method (Maxam and Gilbert, 1980) and by plasmid sequencing according to the protocol devised by Pharmacia.

For sequence analysis of the genomic locus 15-18 bp synthetic primers derived from the FIL2 CDNA sequence were used for plasmid sequencing.

\section{Preparation of a FIL2-cl fusion protein and a FIL2- specific antiserum}

The FIL2-cl fusion protein was generated in the pEAdHindIII expression vector system. This derivative of the vector pEA305 (Amann et al., 1983) was kindly provided by Dr Michael John.

The overexpression of the fusion protein (PEAFIL2) was performed as described in John et al. (1985). pEAFIL2 was purified by using reverse phase and Superdex-200 columns (Pharmacia) and the FIL2-specific antiserum was obtained by injections of the fusion protein into rabbits. After four boosts the serum was affinity-purified by passing over a Sepharose 4LB column (Pharmacia) which had been loaded with the fusion protein. After several washing steps the bound antibodies were eluted by applying $0.2 \mathrm{M}$ glycine ( $\mathrm{pH} 2.7$ ) to the column. 


\section{Western blotting techniques}

Plant material was ground in PBS buffer containing $10 \mathrm{mM}$ EDTA, $14 \mathrm{mM} \beta$-mercaptoethanol, $1 \%$ Triton X100, Polyclar AT and the protease inhibitors leupeptin, pepstatin and aprotinin (Boehringer Mannheim). For Western blotting, the proteins were separated by SDS-PAGE (Laemmli, 1970) and transferred to Hybond ECL nitrocellulose filters (Amersham). The filters were blocked by pre-incubation with $5 \%$ goat serum, $1 \%$ BSA in PBS for $1 \mathrm{~h}$ and incubated with the purified antibodies, or with the unpurified serum (dilution $1 / 10^{4}$ ), for $1 \mathrm{~h}$ at room temperature in PBS, $1 \%$ goat serum, $0.2 \%$ BSA, $0.5 \%$ Tween 20 (Sigma). After washing $(2 \times 5 \mathrm{~min})$ in PBS, $1 \%$ goat serum, $0.2 \%$ BSA, $1 \%$ Tween 20 the filters were incubated with anti-rabbit antibodies (dilution 1/30 000) linked to horseradish peroxidase (Bio-Rad) using the same incubation conditions as described above, followed by four washing steps. The bound antibodies were detected by the ECL method (Amersham).

\section{$\mathrm{N}$-glycosidase $\mathrm{F}$ treatment and lectin affinity chromatography}

Stamen proteins $(100 \mu \mathrm{g})$ were incubated at $90^{\circ} \mathrm{C}$ for $2 \mathrm{~min}$ in PBS, $1 \%$ SDS. After dilution in 10 volumes PBS, $0.5 \%$ n-octylglycoside the sample was incubated again for $2 \mathrm{~min}$ at $90^{\circ} \mathrm{C}$. $\mathrm{N}$-glycosidase $\mathrm{F}$ (Boehringer Mannheim) was added (2.0 u) and the mixture was incubated at $37^{\circ} \mathrm{C}$ for $16 \mathrm{~h}$. During the reaction aliquots were taken from the mixture after different incubation times ( $1 \mathrm{~min}$ to $4 \mathrm{~h}$ ) and boiled in Laemmli buffer. To identify the type of glycosyl chain the lectins Con A and GNA (Boehringer Mannheim) were linked to CNBr-activated Sepharose (Pharmacia). Columns were loaded with the linked lectins and used for affinity chromatography. Stamen proteins in PBS were applied first to the Con A-column to purify glycoproteins with glycose or mannose residues in their glycan chain. After washing with 10 volumes PBS, $0.1 \%$ Tween 20 the bound material was eluted by $0.5 \mathrm{M} \alpha$-methyl-mannoside in PBS. To extract high mannosetype glycoproteins with terminal Man $(\alpha 1-3)$ Man units, the eluted sample was dialysed against PBS and applied to the GNA column using the same procedure as with the Con A column.

\section{Immunocytochemistry}

After fixation either in $4 \%$ formaldehyde $/ 0.5 \%$ glutaraldehyde or in ethanol/acetic acid, inflorescences or young flower buds were embedded in paraffin. The sections were mounted on gelatinecoated slides, which were pretreated according to the procedure described by Huijser et al. (1992). The pre-incubation, the first incubation with the FIL2-specific antiserum (dilution 1/1000), the second incubation using gold-labelled anti-rabbit antibodies (Pierce) and the silver enhancement were performed according to the protocol provided by Amersham.

For transmission electron microscopy, the grids were processed at room temperature as described below. The sections were incubated in PBS, pH 7.2, containing $0.5 \%$ BSA, $0.1 \%$ Tween 20 (PBST) and normal goat serum (1:20) for $50 \mathrm{~min}$. Then the grids were floated in PBST containing affinity-purified antiFIL2 serum diluted 1:100 and normal goat serum for $3 \mathrm{~h}$. The grids were washed with PBST and then incubated for $60 \mathrm{~min}$ in PBST (pH 8.2) containing goat anti-rabbit immunoglobulins $(1: 100)$ coupled to $5 \mathrm{~nm}$ or $10 \mathrm{~nm}$ gold particles (Amersham). After washing with PBST and distilled water the sections were stained with uranylacetate and lead. Controls were performed by incubating the sections with pre-immune serum instead of the primary antibody.

\section{Acknowledgements}

We wish to acknowledge the excellent technical assistance of Rita Berndtgen and Isa Will. We also thank Peter Huijser and Alfons Gierl for helpful advice on in situ hybridization and protein purification, respectively, as well as Candice Sheldon for correcting the English. This work was supported by the Deutsche Forschungsgemeinschaft (SFB 243) to Z. S.-S.

\section{References}

Adair, W.S. and Mecham, R.P. (1990) Organization and assembly of plant and animal extracellular matrix. In Biology of the Extracellular Matrix (Adair, W.S. and Mecham, R.P., eds) New York: Academic Press, pp. 15-84.

Amann, E., Brosius, J. and Ptashne, M. (1983) Vectors bearing a hybrid trp-lac promotor useful for regulated expression of cloned genes in E.coli. Gene, 25, 167-178.

Braun, T., Schofleld, P.R. and Sprengel, R. (1991) Aminoterminal leucine-rich receptors determine hormone selectivity. EMBO J. 10, 1885-1890.

Bronner-Fraser,M. (1990) Cell interactions in development. (Bronner-Fraser, M., ed.) In Seminars in Developmental Biology, Volume 1. Philadelphia: Saunders Scientific Publications, pp. 3-45.

Coen, E.S. and Meyerowitz, E.M. (1991) The war of the whorls: genetic interactions controlling flower development. Nature, 353, 31-37.

Dzelzkalns, V.A., Nasrallah, J. and Nasrallah, M.E. (1992) Cell-cell communication in plants: self-incompatibility in flower development. Devel. Biol. 153, 70-82.

Hashimoto, C., Hudson, K.L. and Anderson, K.V. (1988) The TOLL gene of Drosophila, required for dorso-ventral embryonic polarity, appears to be a transmembrane protein. Cell, 52, 269-279.

Hayes, T.E., Sengupta, P. and Cochran, B.H. (1988) The human $c$ fos serum response factor and the yeast factors GRM/PRTF have related DNA-binding specificities. Genes Devel. 2, 1713-1722.

von Heijne, G. (1986) A new method for predicting signal sequence cleavage sites. Nucl. Acid Res. 14, 4683-4690.

Huljser, P., Klein, J., Lönning, W.-E., Meljer, H., Saedler, H. and Sommer, H. (1992) Bracteomania, an inflorescence anomaly, is caused by the loss of function of the MADS-box gene SQUAMOSA in Antirrhinum majus. EMBO J. 11, 1239-1249.

John, M., Schmidt, J., Wleneke, U., Kondorosi, E., Kondorosi, A. and Schell, J. (1985) Expression of the nodulation gene nod $C$ of Rhizobium meliloti in $E$. coli: role of the nod $C$ gene production in nodulation. EMBO J. 4, 2425-2430.

Kataoka, T.D., Broek, D. and Wigler, M. (1985) DNA sequence and characterisation of the $S$. cerevisiae gene encoding adenylate cyclase. Cell, 43, 493-505.

Krusius, F. and Ruosiathi, E. (1986) Primary structure of an extracellular matrix proteoglycan core protein deduced from cloned cDNA. Proc. Natl Acad. Sci. USA, 83, 7683-7687.

Laemmli, U.K. (1970) Cleavage of structural proteins during the assembly of the head of bacteriophage T4. Nature, 333, 866-869.

Lopez, J.A., Chung, P. W., Fujlkawa, K., Hagen, F.S., Davie, 
E.W. and Roth G.J. (1987) Cloning of the $\alpha$-chain of human platelet glycoprotein 1b: a transmembrane protein with homology to leucine-rich $\alpha$-glycoprotein. Proc. Natl Acad. Sci. USA, 84, 5615-5619.

Lord, E.M. and Sanders, L.C. (1992) Roles for the extracellular matrix in plant development and pollination: a special case of cell movement in plants. Dev. Biol. 153, 16-28.

Maxam, A. and Gilbert, W. (1980): Sequencing end labelled DNA with base-specific chemical cleavage. Methods Enzymol. 65, 499-560.

Nacken, W., Huijser, P., Beltran, J.P., Saedler, H. and Sommer, H. (1991) Molecular characterization of two stamenspecific genes, tap 1 and fil 1 , that are expressed in the wild type, but not in the deficiens mutant of Antirrhinum majus. Mol. Gen. Genet., 229, 129-136.

Nasrallah, J.B., Yu, S.-M. and Nasrallah, M.E. (1988) Selfincompatibility genes of Brassica oleracea: expression, isolation, and structure. Proc. Natl Acad. Sci. USA, 85, 5551-5555.

Pollock, R. and Treisman, R. (1991) Human SRF-related proteins: DNA-binding properties and reguatory targets. Genes Devel. 5, 2327-2341.

Reinke, R., Krantz, D.E, Yen, D., and Zipursky, S.L. (1988) Chaoptin, a cell surface glycoprotein required for Drosophila photoreceptor cell morphogenesis, contains a repeat motif found in yeast and human. Cell, 52, 291-301.

Roberts, K. (1990) Structures at the plant cell surface. Curr. Opinions Cell Biol. 2, 920-928.

Ruoslahti, E. (1989) Proteoglycans in cell regulation. J. Biol. Chem. 204, 13 369-13 372.

Schneider, D.S., Hudson, K.L., Lin, T.Y. and Anderson, K. (1991) Dominant and recessive mutations define functional domains of TOLL, a transmembrane protein required for dorsal-ventral polarity in the Drosophila embryo. Genes Devel. 5, 797-806.

Schwarz-Sommer, Z., Huijser, P., Nacken, W., Saedler, H. and Sommer, H. (1990) Genetic control of flower development by homeotic genes in Antirrhinum majus. Science, 250, 931-936.

Schwarz-Sommer, Z., Hue, I., Huijser, P., Flor, P., Hansen,R., Tetens, F., Lönning, W.-E., Saedler, H. and
Sommer, H. (1992) Characterization of the Antirrhinum floral homeotic MADS-box gene deficiens: evidence for DNA binding and autoregulation of its persistent expression throughout flower development. EMBO J. 11, 251-263.

Shibuya, N., Goldstein, I.J., van Damme, E.J.M. and Peumanns, W.J. (1988) Binding properties of a mannosespecific lectin from the snow drop (Galanthus nivalis) bulb. J. Biol. Chem. 263, 728-734.

Sommer, H., Beltran, J.-P., Huijser, P., Pape, H., Lönning, W.-E., Saedler, H. and Schwarz-Sommer, Z. (1990) Deficiens, a homeotic gene involved in the control of flower morphogenesis in Anthirrhinum majus: The protein shows homology to transcription factors. EMBO J. 9, 605-613.

Stein, J.C., Howlett, B., Boyes, D.C., Nasrallah, M. and Nasrallah, J.B. (1991) Molecular cloning of a putative receptor protein kinase gene encoded at the self-incompatibility locus of Brassica oleracea. Proc. Natl Acad of Sci. USA, 88, 8816-8820.

Takahashi, N., Takahashi, Y. and Putnam, F.W. (1985) Periodicity of leucine and tandem repetition of a 24-amino acid segment in the primary structure of leucine-rich $\alpha_{2}$-glycoprotein of human serum. Proc. Natl Acad. Sci. USA, 82, 4767-4771.

Toblas, Ch.M., Howlett, B. and Nasrallah, J.B. (1992) An Arabidopsis thaliana gene with sequence similarity to the S-locus receptor kinase of Brassica oleracea. Plant Physiol. 99, 284-290.

Tröbner,W., Ramirez, L., Motte, P., Hue, I., Huijser, P., Lönnig, W.-E., Saedler, $H_{\text {, }}$ Sommer, $H$. and SchwarzSommer, Zs. (1992) GLOBOSA: a homeotic gene which interacts with DEFICIENS in the control of Antirrhinum floral organogenesis. EMBO J. 11, 4693-4704.

Walker, J.C. (1993) Receptor-like protein kinase genes of Arabidopsis thaliana. Plant J. 3, 451-456

Walker, J.C. and Zhang, R. (1990) Relationship of a putative receptor protein kinase from maize to the S-locus glycoproteins of Brassica. Nature, 345, 743-746.

Yamaguchi, Y. and Ruoslahti, E. (1988) Expression of human proteoglycan in chinese hamster ovary cells inhibits cell proliferation. Nature, 336, 244-246.

EMBL Data Library accession number X76995 (FIL2 gene). 